\title{
Da escola à natureza: uma experiência de Educação Ambiental em área protegida na cidade do Rio de Janeiro
}

From school to the nature: an experience of Environmental Education in protected areas of Rio de Janeiro city

\author{
Nadja Maria Castilho da Costa \\ e Vivian Castilho da Costa ${ }^{2}$
}

\section{Introdução}

As escolas brasileiras, tanto do ensino fundamental como médio, tem sido estimuladas a desenvolver projetos e ações de Educação Ambiental (EA), sendo o professor o responsável por sua inserção nas práticas pedagógicas cotidianas, em consonância com o que recomenda o Programa Nacional de Educação Ambiental Brasileiro (ProNEA) ${ }^{1}$ e a Política Nacional de Educação Ambiental (PNEA) $)^{2}$, instituídos na década de 1990. No Pro$\mathrm{NEA}^{1}$, uma das 5 linhas de ação é a criação de uma rede de centros especializados em EA integrando universidades, escolas profissionais e centros de documentação em todos os Estados brasileiros ${ }^{1}$.

$\mathrm{Na}$ maioria das vezes, as aulas de Ciências e Geografia, ao abordarem o tema meio ambiente/ ecossistemas, não usam exemplos referentes ao cotidiano do aluno, prejudicando o processo de aprendizagem e o objetivo previsto no Parâmetro Curricular Nacional - $\mathrm{PCN}^{3}$ : "perceber-se integrante, dependente e agente transformador do ambiente, identificando seus elementos e as interações entre eles, contribuindo ativamente para a melhoria do meio ambiente."”.

As questão principais são: será que os professores estão preparados para trabalhar com seus alunos a questão ambiental? Será que eles detém o conhecimento da realidade local e de seus problemas ambientais a ponto de capacitar seus alunos na defesa e conservação dos recursos naturais da região? Hoje em dia, percebe-se que os projetos educacionais promovem visões mais conservadoras e outras vezes mais críticas. Segundo Mezomo et $\mathrm{al}^{4}$, durante muitos anos a Educação Ambiental tinha o enfoque apenas de conscientização, mas a visão de que a conscientização sozinha irá resolver tudo, vem sendo substituída pelas ações e práticas

\section{Resumo}

As áreas protegidas localizadas na cidade do Rio de Janeiro apresentam, em seu entorno próximo, escolas do ensino fundamental e médio que se encontram desconectadas da realidade ambiental local. $\mathrm{O}$ objetivo do presente trabalho é relatar as experiências em Educação Ambiental do projeto extensionista intitulado "A Escola e o Parque Estadual da Pedra Branca (PEPB)", em desenvolvimento nas escolas municipais e particulares, próximas aos remanescentes de Mata Atântica protegidos pelo referido Parque. O projeto (em desenvolvimento há mais de dez anos) visa capacitar professores e alunos no conhecimento da realidade geoambiental da área, formando uma rede de atores sociais que tem como objetivo primordial, a curto e médio prazos, contribuir no manejo e conservação da maior área protegida da cidade do Rio de Janeiro. Apesar das dificuldades encontradas na capacitação de professores e alunos das escolas contempladas, a metodologia utilizada, calcada nas práticas cognitivas e de experienciação propostas no manual do professor, mostrou-se eficaz no processo de inserção comunitária no processo de conservação dos recursos naturais, interagindo as ações da sociedade local com a administração da área protegida - PEPB.

Palavras-chaves: Educação Ambiental; Área Protegida; Escola

Área da extensão: Meio Ambiente Linha da extensão: Questões Ambientais 
efetivas, onde a EA pode ser tratada não só nas escolas, mas também na comunidade.

É neste contexto, de convicção da carência de práticas educativas dentro e fora das escolas e que trabalhem a questão ambiental local, que o projeto foi desenvolvido.

A proposta é inserir nas escolas de ensino fundamental da rede pública e privada, do entorno da maior área protegida da cidade do Rio de Janeiro: Parque Estadual da Pedra Branca PEPB, a Educação Ambiental local criando uma rede de conhecimento sobre a realidade que os cerca e sobre as formas em que a sociedade local pode contribuir para a sua proteção.

O trabalho abordará dentro de uma visão analítica, as linhas de atuação do projeto, bem como as principais dificuldades encontradas na efetiva implantação e implementação da referida rede.

\section{O que é o Projeto "A Escola e o Parque Estadual da Pedra Branca"?}

Trata-se de um projeto extensionista de iniciativa do Grupo de Estudos Ambientais da Universidade do Estado do Rio de Janeiro - GEA/ UERJ, em desenvolvimento junto a comunidades do interior e entorno próximo ao Parque Estadual da Pedra Branca - PEPB, localizado na Zona Oeste da cidade do Rio de Janeiro - RJ (Brasil).

Durante mais de uma década de realização de trabalhos científicos no interior e periferia próxima ao $\mathrm{PEPB}^{5,6,7,8}$ foi possível perceber a existência de algumas lacunas na formação de professores do ensino fundamental, no que diz respeito aos conhecimentos relacionados ao ambiente local (características físicas, tais como as características do relevo, da hidrografia, dos atrativos turísticos, da legislação ambiental local, entre outros aspectos), bem como a carência de percepção sobre os problemas que afetam os recursos naturais (principais impactos ambientais, como lixo, poluição dos recursos hídricos, deslizamentos de encostas e inundações, entre outros) e de como mitigá-los. A partir de então, foi organizado um programa de atividades teóricas e práticas com ênfase na questão ambiental local, principalmente sobre a realidade do PEPB, sintetizado num manual instrutivo ${ }^{6}$. O manual é dirigido ao professor e visa orientá-lo no desenvolvimento de atividades de Educação Ambiental, bem como a efetivação das práticas propostas, dando-lhe autonomia de ação com seus alunos. Através dele, professores e alunos, prioritariamente da $4^{\mathrm{a}}$ e $5^{\mathrm{a}}$ séries $\left(5^{\circ}\right.$ e $6^{\circ}$ anos) do ensino fundamental, durante um semestre letivo, se capacitam, contando com a aprovação e supervisão do Conselho Regional de Ensino - CRE, responsável por cada região. A estimativa média semestral é de 4 turmas por escola, sendo 2 turmas de cada série, compreendendo, aproximadamente 120 alunos no total e 4 professores.

Assim sendo, o objetivo central do programa é difundir os conhecimentos adquiridos pela comunidade científica, tanto para professores, quanto para alunos das escolas e comunidades próximas ao Parque Estadual da Pedra Branca, de forma a torná-los elos de ligação entre a escola e a administração da área protegida (INEA - Instituto Estadual do Ambiente - RJ), envolvendo todos os atores sociais na busca de uma relação harmônica, justa e ativa com o ambiente próximo de onde vivem (de onde moram) e estudam (de suas escolas).

Desde o início do projeto, no ano de 2001, foram contempladas 25 escolas, sendo a maioria da rede pública municipal (23). Inicialmente o GEA se dirigia a cada escola e acompanhava (vivenciava) todo o processo de capacitação, atuando em conjunto com os professores e alunos. Posteriormente, adotou-se como procedimento a vinda de professores à UERJ, com o objetivo de promover a capacitação de um conjunto maior de professores na utilização do referido manual, na expectativa de torná-los difusores de conhecimento e sensibilizá-los para o uso desse instrumento didático em prol da difusão da Educação Ambiental, conforme será detalhado a seguir.

\section{A Educação Ambiental local no cotidiano das escolas do entorno do Parque Estadual da Pedra Branca: realidade ou utopia?}

O projeto "A escola e o Parque Estadual da Pedra Branca" completa 10 anos de atividades e faz um balanço dos aspectos positivos e dos obstáculos encontrados no seu desenvolvimento. A ideia inicial do projeto foi realizada durante os cinco primeiros anos; portanto, até a metade de sua existência visava formar uma rede de conhecimento e sensibilização ambiental em todas as escolas do ensino fundamental, localizadas no entorno próximo ao $\mathrm{PEPB}$, em uma faixa de $1 \mathrm{~km}$ a partir dos limites 
da área protegida. Conforme destacado por Costa \& Costa ${ }^{4}$, a proposta básica baseava-se no princípio educativo "natureza que nos cerca", articulando os conceitos de "Identidade, Espaço, Tempo e Transformação", enfocando problemas concretos que se impõem às comunidades que vivem próximas aos remanescentes florestais.

Numa primeira seleção, foram cadastradas um total de 97 escolas da rede municipal. Posteriormente, agregamos a estas, as escolas da rede particular elevando o número para 256 escolas.

Durante a segunda metade do projeto, de 2007 a 2009, houve uma segunda e última seleção com a adoção de um novo método diferenciado de execução. Uma primeira fase do novo método era selecionar três escolas mais próximas do PEPB: E. M. Azul Branco, em Realengo; E. M. Francis Hime na Taquara e E. M. Alfredo Cesário Alvim, em Campo Grande, onde as atividades foram presenciais, ou seja, a coordenação do projeto, juntamente com a equipe de bolsistas e professores voluntários do Grupo de Estudos Ambientais - GEA do Departamento de Geografia Física da UERJ, implementaram os 10 módulos educativos constantes do manual do professor, tendo o acompanhamento dos professores de cada turma.

Em uma segunda etapa (de 2010 a 2011), outros professores foram contactados visando realizar a capacitação no uso e aplicação do manual do professor. Foram contactadas 25 escolas municipais, compreendendo pelo menos 1 professor de cada escola que lecionasse para alunos da $4^{\mathrm{a}}$ e $5^{\mathrm{a}}$ séries ( $5^{\circ}$ e $6^{\circ}$ anos) do ensino fundamental.

Isso significa que, durante os últimos cinco anos, o projeto foi efetivamente desenvolvido em sua plenitude, envolvendo todos os componentes de cada escola: diretores, orientadores pedagógicos, professores e alunos. Para cada módulo foram realizadas várias atividades, tanto intraclasse, como extraclasse, que serviram de aprendizado e motivação para uma efetiva conscientização ambiental, voltada à realidade local. $\mathrm{O}$ objetivo de cada atividade, principalmente as de natureza extraclasse, é sensibilizar alunos e professores envolvidos sobre os problemas ambientais locais, permitindo que ambos reflexionem sobre como contribuir para a mitigação dos danos que vêm sendo provocados aos recursos naturais do entorno da escola. Este procedimento, particularizado para cada escola, perdurou por dois anos, sendo substituído por outra metodologia de trabalho, a seguir descrita.

$\mathrm{Na}$ tentativa de formar a referida rede, a equipe do GEA/UERJ adotou novos procedimentos de trabalho: ao invés de ir em cada escola desenvolver as atividades, buscou-se trazer os professores à Universidade, realizando a capacitação simultânea de cerca de 60 docentes (do início do projeto até o ano de 2012), preparando-os para aplicarem em suas escolas, a metodologia detalhada no manual. Cada professor recebeu um Kit de material gerado pela equipe do GEA, contendo: um CD explicativo do manual e um texto de apresentação (informações gerais) do projeto.

Após cada etapa (reunião) de capacitação, o GEA se colocava à disposição dos professores contemplados visando dar todo suporte operacional durante a implantação ou implementação do projeto em suas escolas. A expectativa gerada ao final de cada reunião era de total adesão por parte do grupo capacitado, mas, na prática, isso não aconteceu.

Durante o primeiro semestre de 2010 foram feitos vários contatos, via internet e por telefone, com todos os professores presentes às reuniões com o objetivo de avaliar, através de questionário, o andamento das atividades em suas escolas. Do total de professores participantes, 8 informaram a evolução do projeto e dois deles disseram que aplicaram o projeto em sala de aula de forma adaptada ao que foi proposto no manual do professor. Isso, de certa forma, reflete uma realidade vivenciada pelas escolas, no que concerne a inserção de novas práticas que fujam ao que foi programado no projeto pedagógico anual.

Mesmo havendo a aprovação da direção da escola quanto à implantação do projeto, a equipe do GEA/UERJ percebeu a necessidade do monitoramento contínuo, passo a passo, de todos os procedimentos adotados pelos professores no sentido de viabilizar, em sala de aula, a Educação Ambiental voltada para a realidade local.

\section{Vivenciar a realidade local como mecanismo de aprendizado coletivo e exercício da cidadania}

Pelas experiências realizadas nas três escolas mencionadas anteriormente, tanto os professores quanto os alunos contemplados com o projeto vi- 
venciaram, junto com a equipe do GEA/UERJ, todas as atividades programadas em cada módulo, num trabalho interativo de aprendizado coletivo. As ações dentro e fora de sala de aula foram motivadoras do conhecimento sobre a realidade socioambiental local, saindo da rotina dos exemplos de problemas e soluções ambientais mencionados nos livros didáticos, em sua grande maioria, distantes do dia a dia de cada um dos alunos da localidade. Estimular esse novo olhar, voltado para "o local onde se vive" criou uma grande expectativa nas escolas, por uma nova postura frente às questões ambientais, na medida em que tornou cada indivíduo um agente efetivo de conservação dos recursos naturais locais e, ao mesmo tempo, um agente multiplicador dessas ações, levando e difundindo em suas casas, junto aos seus familiares, uma nova maneira de ver e entender o seu entorno. Isso talvez tenha sido a principal razão do êxito do trabalho interativo Universidade-Escola.

Por sua vez, o professor de ensino fundamental e médio necessita de novos estímulos para acrescentar à sua árdua tarefa docente, atividades que transformem a sua visão de mundo e os tornem verdadeiros atores sociais exercendo, de fato, a sua cidadania. Neste sentido, a presença continuada de uma equipe motivadora, como foi a equipe do GEA/UERJ, foi decisiva para o sucesso do projeto. A tentativa de torná-los (os professores) autônomos no processo de implementação das atividades junto aos alunos criou uma lacuna na motivação inicial o que pode ter contribuído pela não continuidade do projeto nas escolas onde a equipe do GEA não se fez presente. Tudo isso agravado pela falta de tempo (e desgaste físico) do professor, para implementar mais uma atividade acadêmica, embora a considere fundamental no aprendizado escolar.

Isso nos fez refletir e reavaliar, metodologicamente, os procedimentos adotados e hoje a nova proposta é retornar ao processo anterior, fazendo os ajustes necessários que envolvam, basicamente, um monitoramento contínuo por parte do GEA, de todas as etapas em andamento nas escolas contempladas.

Tanto alunos, quanto professores se sentem mais motivados quando uma equipe externa atua na escola, mesmo que esta não permaneça todo o tempo em sala de aula. Na prática, o professor é tão aprendiz quanto seu aluno e busca na Universidade efetuar uma reciclagem quanto aos conhecimentos ambientais, principalmente quando estes dizem respeito à realidade que o cerca. Segundo Freire?: "Ensinar inexiste sem aprender e vice-versa" e neste processo o professor deve ter a consciência da necessidade de investir parte de seu tempo no trabalho de autoaprendizado. Quando isso acontece, o sucesso do projeto está garantido. É com essa premissa que o GEA vem obtendo êxito em suas atividades de Educação Ambiental.

\section{Considerações finais}

A análise das experiências e impasses aqui relatados serviu de base para a realização de ajustes e modificações nos procedimentos pedagógicos adotados nas escolas contempladas pelo Projeto "A escola e o Parque Estadual da Pedra Branca". Atualmente, o GEA promove a ida de professores à Universidade e analisa e debate com eles o conteúdo do manual, assessorando-os na implementação das práticas educativas junto aos alunos, em suas escolas.

Trabalhar interativamente Escola-Universidade parece ser a forma mais eficaz de promover a cognição ambiental, quando se trata de capacitar alunos e professores sobre os problemas socioambientais locais.

A proposta é retomar as escolas já contempladas visando reativar as atividades, bem como iniciar com novas escolas do entorno da área protegida seguindo a premissa da interação continuada, procurando inclusive dar ênfase as práticas extra-classe, dentro da ótica da experenciação e contato com a natureza. Essa, seguramente, é uma das muitas formas que temos para contribuir para a manutenção do que ainda resta da maior floresta urbana do mundo - o Parque Estadual da Pedra Branca - PEPB.

\section{Contribuição dos autores}

Nadja Maria Castilho da Costa, professora adjunta do DGF-IGEOG da Universidade do Estado do Rio de Janeiro (UERJ), foi responsável pela orientação do projeto, pela elaboração e execução das atividades desenvolvidas pelo Grupo de Estudos Ambientais (GEA) com o grupo de professores e suporte nas atividades com alunos do ensino fundamental das escolas públicas con- 
templadas com o projeto. Além disso, foi responsável pela elaboração do relato de experiência.

Vivian Castilho da Costa, também professora adjunta do DGF-IGEOG (UERJ), foi corresponsável pela elaboração e execução das atividades do GEA-UERJ com os professores, além de contribuir para elaboração e revisão do relato de experiência.

\section{Referências}

1. ProNEA. Programa Nacional de Educação Ambiental. Disponível em: <http://www.paralelos.psc.br/meio_ambiente/org_gest/pronea/arqs/pronea3.pdf $>$. Acesso em: 22 jul. 2011.

2. PNEA. Política Nacional de Educação Ambiental. Disponível em: <http://www.infoescola.com/meio-ambiente/ politica-nacional-de-educacao-ambiental-pnea/>. Acesso em: 22 jul. 2011.

3. BRASIL. Ministério da Educação. Secretaria de Educação Fundamental. Parâmetros curriculares nacionais: terceiro e quarto ciclos do ensino fundamental: Língua Portuguesa. Brasília: MEC/SEF, 1998. Disponível em: <http://zinder.com. br/legislacao/pen-fund.htm>. Acesso em: 22 jul. 2011.

4. MEZOMO, Águeda Marcéi; CALCANHOTO, Flávio; BALDASSO, Nelson Antonio. A experiência da Educação Ambiental no município de Lindolfo Collor/RS - Superando as fronteiras entre educação formal e não formal.
In: Encontro Nacional da ECOECO, V. Caxias do Sul, RS. 2003. Mesa 5. Disponível em: <http://www.ecoeco.org.br/ conteudo/publicacoes/encontros/v_en/Mesa5/2.pdf $>$. Acesso em: 08 jul. 2012.

5. COSTA, Vivian Castilho da; COSTA, Nadja Maria Castilho da. Educação Ambiental pelo ecoturismo em unidades de conservação: uma proposta efetiva para o Parque Estadual da Pedra Branca - RJ. In: PEDRINI, A. de G. (Org.). Ecoturismo e educação ambiental. Rio de Janeiro: Publit, 2005. p. 39-65.

6. COSTA, Nadja Maria Castilho da; COSTA, Vivian Castilho da (Orgs.). Manual de Educação Ambiental para o Professor do Ensino Fundamental: a Escola e o Parque Estadual da Pedra Branca. Livro do Autor, Rio de Janeiro, RJ, 135 p., 2007.

7. COSTA, Nadja Maria Castilho da; COSTA, Vivian Castilho da. Educação Ambiental para Professores do Ensino Fundamental: a Experiência do Grupo de Estudos Ambientais (GEA/UERJ) nas Trilhas do Parque Estadual da Pedra Branca-RJ. In: COSTA, N. M. da; COSTA, V. C. da; NEIMAN, Z. (Orgs.). Pelas Trilhas do Ecoturismo. Rio de Janeiro. Ed. Rima, 2008. p. 101-119.

8. COSTA, Nadja Maria Castilho da; COSTA, Vivian Castilho da; LIMA, Andréa Pereira de Lima; VIRTUOSO, Anadelson Martins; FURTADO, Patrícia. A inserção das escolas no conhecimento e conservação dos recursos naturais do Parque Estadual da Pedra Branca - RJ. In: SAPIS Seminário Áreas Protegidas e Inclusão Social, II. Programa EICOS-IP/UFRJ. 2006. Disponível em: <http://www.ivt-rj.net/ sapis/2006/pdf/NadjaCosta.pdf>. Acesso em: 05 jul. 2012.

9. FREIRE, Paulo. Pedagogia da autonomia: saberes necessários à prática educativa. São Paulo: Paz e Terra,1996, p. 75-92.

\begin{abstract}
In Rio de Janeiro city one can find several elementary and secondary schools in the protected area surroundings whose frequenter people ignores the local environmental reality. This paper aims to describe experiences in Environmental Education observed in developing an extension project applied to county or private schools in the remaining Atlantic Forest, protected by the State Park of Pedra Branca. The project (being developed since ten years ago) intend to improve capabilities of teachers and students in knowledge of environmental reality of the area, generating a net of social actors whose main objective, in short and long term, is to contribute in management or handling and conservation of the greater protected area of Rio de Janeiro city. Keywords: Environmental Education; Protect Area; Schools
\end{abstract}

